\title{
The Mysteries of the Baratti Amphora
}

\author{
Claudio Arias ${ }^{1}$, Stefano Pagnotta ${ }^{2}$, Beatrice Campanella ${ }^{2}$, Francesco Poggialini $^{2}$, Stefano Legnaioli ${ }^{2}$, \\ Vincenzo Palleschi ${ }^{2 *}$ and Cinzia Murolo ${ }^{3}$
}

${ }^{1}$ Retired Professor of Archaeometry, University of Pisa, Italy

${ }^{2}$ Institute of Chemistry of Organometallic Compounds, CNR Research Area, Pisa, Italy

${ }^{3}$ Curator at Museo Archeologico del Territorio di Populonia, Piazza Cittadella, Piombino, Italy

*Corresponding author: Vincenzo Palleschi, Institute of Chemistry of Organometallic Compounds, CNR Research Area, Pisa, Italy.

Received Date: April 22, 2019

Published Date: May 08, 2019

\begin{abstract}
The Baratti Amphora is a magnificent silver vase, casually recovered in 1968 from the sea in front of the Baratti harbor, in Southern Tuscany. Since its discovery, very few certain information has been drawn about its history, provenience and destination. Previous archaeometric studies and the iconography of the vase might suggest a late antique realization, possibly in an Oriental workshop (Antioch). A recent study, performed by the National Research Council of Pisa in collaboration with the Populonia Territory Archaeological Museum, in Piombino, has led to a detailed study of the Amphora, both from a morphological point of view through the photogrammetric reconstruction of a high-resolution 3D model, and from the point of view of the analysis of the constituent material, using a portable X-Ray Fluorescence (XRF) instrumentation. In particular, the XRF analysis has led to a reconsideration of the archaeometric measurements done in the last century. After this study, the knowledge of the Baratti Amphora has been significantly improved, opening the way to new provenience studies that could shed new light on its mysteries.
\end{abstract}

Keywords: Archaeometry; Mystery cults; X-Ray fluorescence; Silver treasure; 3D photogrammetry

\section{Natural and Cultural Landscape}

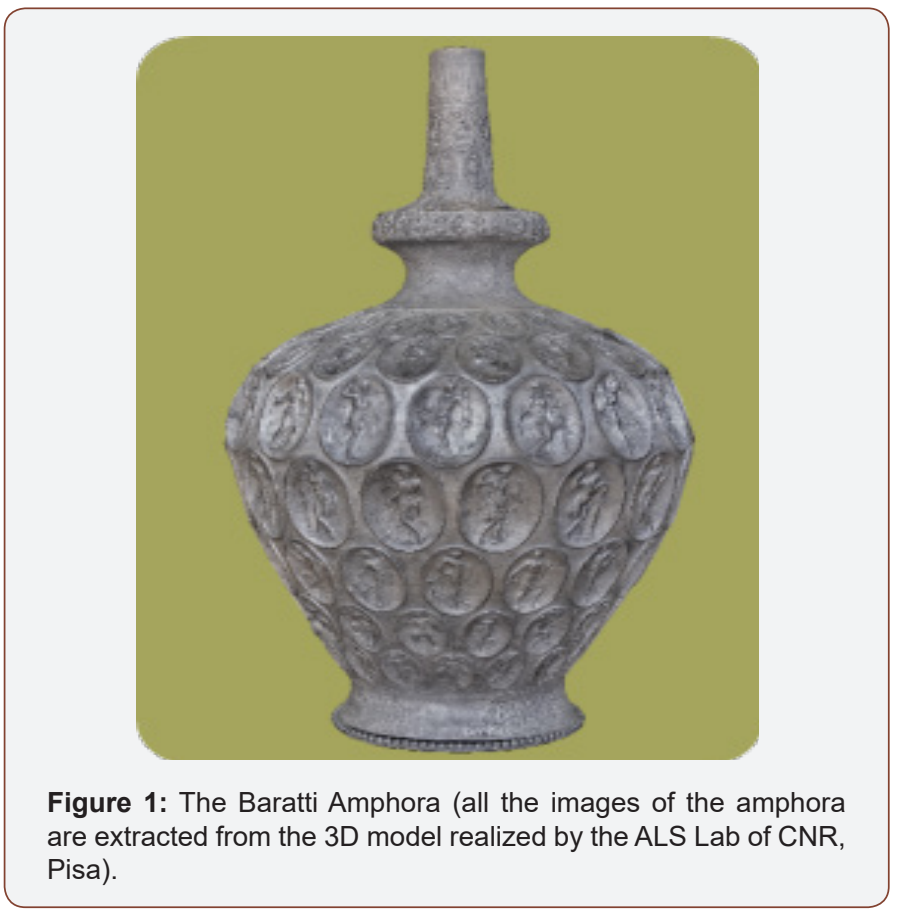

The Baratti Amphora is a silver vase of about $60 \mathrm{~cm}$ of height, and $35 \mathrm{~cm}$ of diameter (Figure 1) it could have contained about 22 liters of liquid. The amphora (remains of the welding of the two handles are still visible in the upper part, (Figure 2) is composed of very pure silver, weighting about $7 \mathrm{~kg}$. The amphora was casually recovered from the bottom of the sea in 1968 by a fisherman. The long permanence in sea water and the mechanical damages suffered during the recovery suggested the need for a long and careful restoration, which was performed at the laboratories of the Florence Archeological Superintendence and lasted several years.

In fact, after the initial cleaning of the marine incrustation on the amphora surface, which was performed in 1972, at the arrival of the amphora in Florence, the archaeologists of the Superintendence had to wait several years before acquiring the confidence needed to face the arduous task of recovering the original shape of the amphora. After a successful test on a less precious silver object, in 1979 the amphora was restored to the original shape, using the combination of local thermal heating of the metal and pressure applied from the inside with a hydraulic jack [1]. 


\section{The Mysteries}

\section{Realization technique}

One of the most puzzling mysteries of the Baratti amphora is the technique used for its realization. The surface of the amphora is decorated, in fact, with 132 oval medallions, organized in 10 registers ( 2 in the upper part of the neck, 1 in the bottom part of the neck and 7 in the body of the amphora). It's still unclear how these medallions were realized. The amphora shows no signs of welding, except for the connection between the body of the vase and its bottom; it was, therefore, realized in a single piece. The hypothesis formulated by the archaeologists at the time of the restoring was that the decorations were realized by forging, using a negative from the inside, at first, and then modified with a chisel to add the minute details of the figures that can be observed today. In support of their hypothesis is the fact that the bottom part of the vase was realized separately, and then welded to the rest of the amphora. The possibility of lost wax casting was explicitly dismissed. The main difficulty that this theory must face is related to the thickness of the amphora walls (comprised between 1 and $2 \mathrm{~mm}$ ) which would make almost impossible the use of negative stamps; moreover, some parts of the amphora are hardly reachable from the inside (bottom of the neck) (Figure 2).

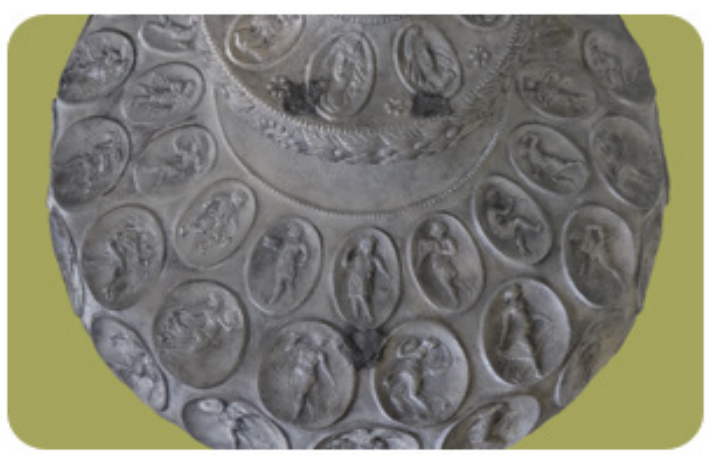

Figure 2: Traces of the points of welding of the amphora handles (now lost).

More recently, Edilberto Formigli, expert of ancient metallurgy, formulated the alternative hypothesis that the amphora was realized using the lost wax casting technique, i.e. that the decoration were realized at the same time of the vase itself [2]. According to Formigli, the medallions could have been realized directly on the casting form, or obtained by pressing suitable stamps on the wax model. In any case, whether the decoration were obtained directly on the metal surface or on a wax intermediate model, it's a matter of fact that the magnificence of the result obtained suggests that the Baratti amphora was realized in an important workshop, where advanced technological techniques could have been mastered for the quick and accurate production of high quality artistic manufacts.

\section{Significance and use}

The shape of the amphora and parts of its decorations, depicting a Dionysian procession in the second and fifth register of the body and Dionysus himself with his wife Ariadne on third one (Figure3), might suggest that the liquid contained in the vase should have been wine (Figure 3).

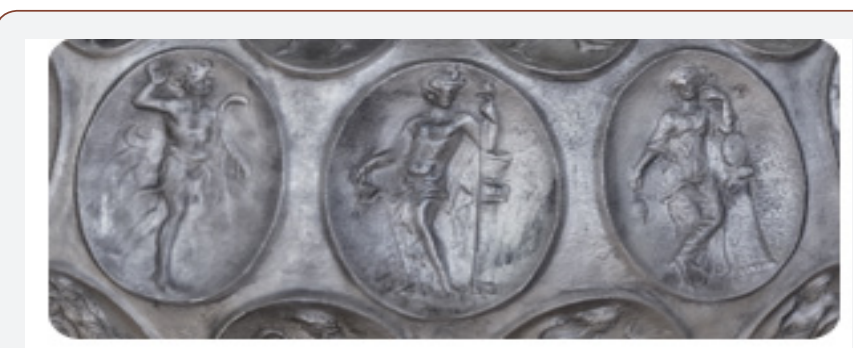

Figure 3: Satyr, Dionysus and Ariadne.

However, it's unclear whether the Baratti amphora was intended for an actual use at the banquet or would have been used only for decorative or ritual purposes. It's similarly unclear at what stage of its life the amphora was lost in the sea of Baratti, from where it was coming and where it was destined. The long permanence under the sea excludes the possibility of analyzing the possible content of the amphora, as was done in Legnaioli et al. (2013) for the study of an ancient oinochoe [3]. From the iconographic point of view, the number and disposition of the medallions themselves reveal an exoteric symbolism based on the Zodiac signs (12 medallions in the first two upper registers of the amphora neck) and seasons and regions of the world ( 8 medallions in the lower register of the neck). The Dionysian procession is depicted in the second and fifth register of the main body of the amphora $(16+16$ medallions), while the first and sixth register $(16+16$ medallions) depicts musicians and dancers. The middle registers represent 32 divinities and mythological figures (16+16 medallions) mostly related to oriental mystery cults as, for example, Dionysus, Attis and Cybele (Figure 4), the Dioscuri, Aphrodite, Paris and Helen of Troy. The last registers (16 medallions) at the bottom of the vase is devoted to the myth of Eros and Psyche (Figure 4).

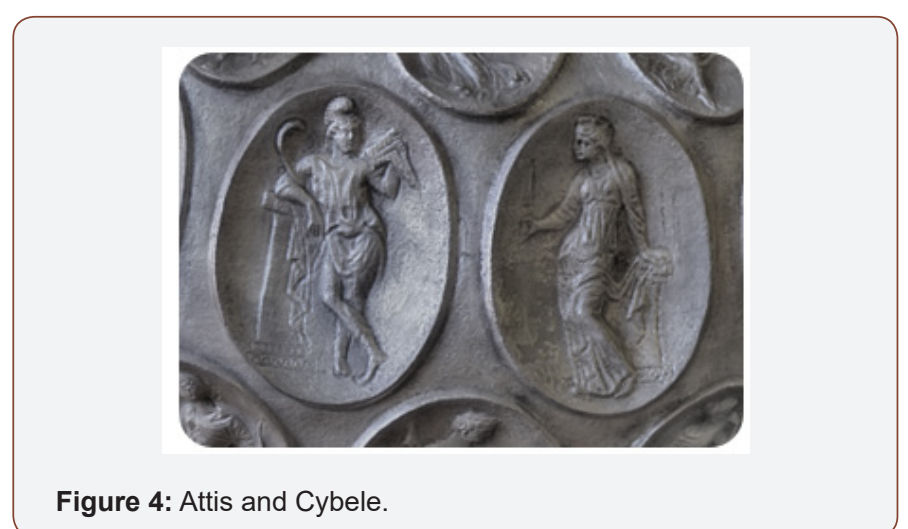

The exoteric symbolism of the medallions (disposed in 7 main registers, as the seven planets of the Ptolemaic system [2]), the presence of iconographic themes clearly referred to oriental mystery myths, the central role of Cybele, all these elements contribute to place the amphora to the late antique period (end of IV century A.D.). Although at that time the Christianism was already the official religion of the Roman empire, in fact the influence of the oriental myths was still strong among the senatorial elite in Rome and in the Italian peninsula. 


\section{Provenience}

The atmosphere of substantial tolerance between Christians and pagans which characterizes the last decades of IV century A.D. does not allow to dismiss the possibility that the Baratti amphora could have been realized in a silver workshop in Rome. Most of the luxury items realized for the senatorial class were in fact produced in Rome, where several workshops were active in the production of golden and silver objects. Being the Baratti amphora a unique object, it's difficult to compare its iconography with other objects of known provenience. A comparison could be made, however, with the coeval Conceşti amphora (recovered in Moldavia and now conserved at the Hermitage museum in St. Petersburg, Russia) and with the amphora of the Seuso Treasure in private collection and now exhibited at the Hungarian National Museum.

Both the amphoras are considered of being of oriental provenience and share with the Baratti amphora the recurrence of mythological figures typical of Asia Minor (Helen of Troy and the judgement of Paris, Cybele and Attis). This similitude would point to a possible common workshop or group of workshops in Antioch on the Orontes, Syria (now Turkey). Antioch was an important center of the Roman empire, and the presence of active precious metals workshops in the last decade of the IV century A.D. is well documented.

Another viable hypothesis is the provenience of the amphora from the Danubian area. This theory arises from the comparison with a cylindrical silver container decorated with medallions coming from Viminacium, in the Roman region of Moesia (today's Kostolac, Serbia) [4]. Unfortunately, the container was stolen during the First World War and further comparisons are not possible anymore (Figure 5).

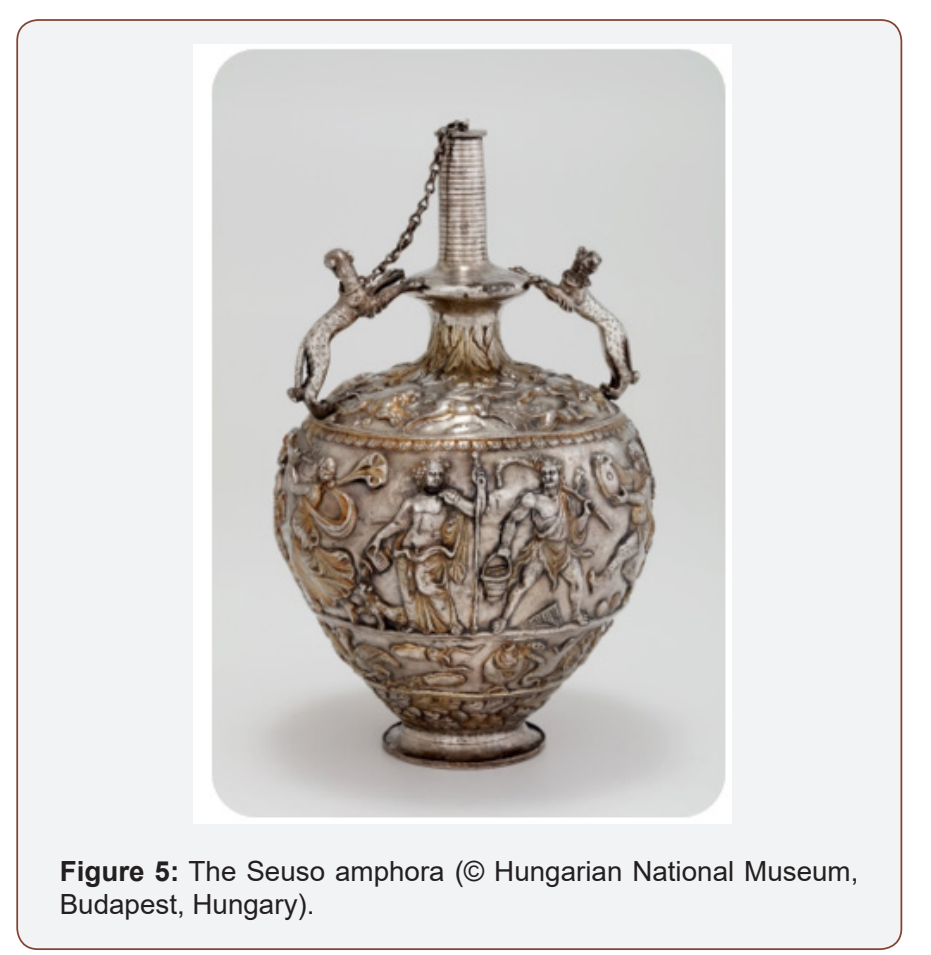

\section{Material composition}

The attribution to an oriental workshop was further supported, in last years, by the interpretation of the archaeometric analysis performed in the Seventies of last century by the archaeologists in charge of the amphora restoration. During the cleaning process a few silver samples were taken from the amphora and analysed qualitatively using a mass spectrometer and quantitatively through Atomic Absorption Spectroscopy (Perkin-Elmer 403 AAS).The analysis revealed that the silver used for the realization of the Baratti amphora was very pure (96-98\%) except in the zones near the welding of the handles and of the bottom part, who appeared contaminated by tin and lead.

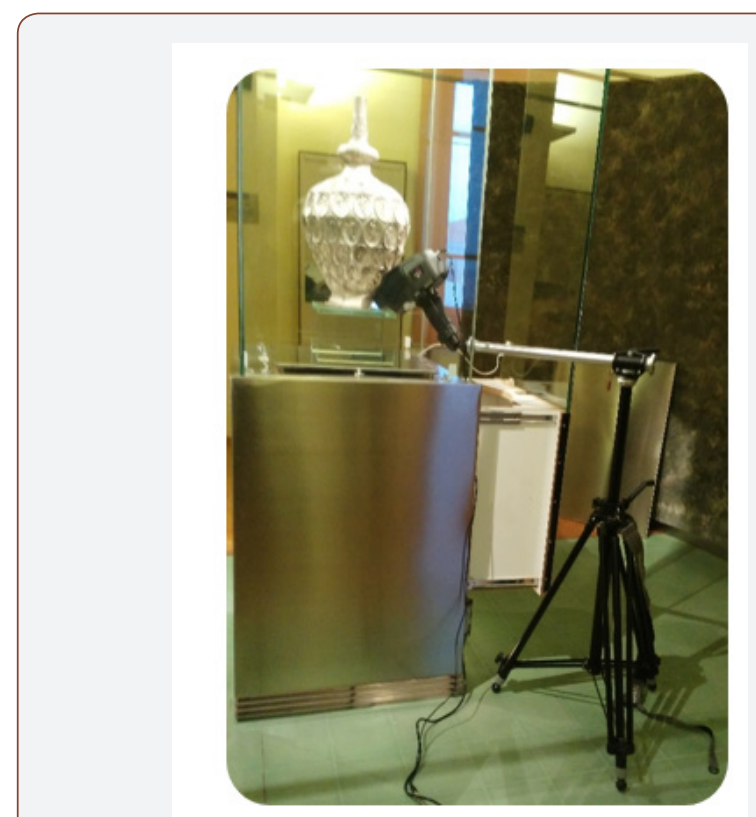

Figure 6: The XRF ELIO Instrument during the analysis of the Baratti amphora. The amphora was not removed from its display at the Museum of Piombino for this analysis.

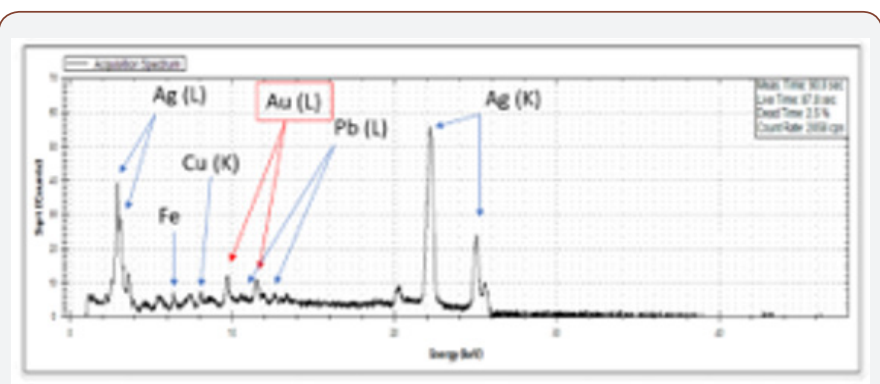

Figure 7: A typical XRF spectrum acquired on the surface of the Baratti amphora. The main fluorescence lines are marked in the figure. Note the square root scale on the $y$ axis.

No trace of gold was found in the silver alloy. Paolo Enrico Arias, author of the 1986 monography on the Baratti amphora [1], interpreting the archaeometric measurements performed by the laboratory of the Florence superintendence wrote: “...la totale assenza di oro porta automaticamente ad escludere che la miniera o le miniere da cui venne estratto fossero costituite da minerali argentiferi e auriferi" ( “... the total absence of gold leads to exclude authomatically that the mine or mines from where the [silver] was extracted were made of silver- and gold-bearing minerals") and, again: "il metallo venne ricavato ... non da giacimenti auriferi, ma da minerale di piombo (galena)" ("the metal was not extracted .... from gold-bearing deposits, but from lead minerals (galena)"). 
The analysis performed by our laboratory was done using the completely non-destructive method of X-Ray Fluorescence (XRF) We used the ELIO Energy-Dispersive portable XRF instrument produced by XGLab (now Bruker). The instrument is light and robust; the maximum energy of the primary X-ray beam is $50 \mathrm{keV}$. The material of the anode is Rh (Figure 6). We analysed more than 30 points on the amphora surface, obtaining very similar XRF spectra. A typical spectrum is shown in (Figure 7).

From the analysis of the XRF spectra, we can confirm the results of the AAS analysis for what concerns the quality of the silver used, which is very pure (Figure 5). Traces of $\mathrm{Fe}, \mathrm{Cu}$ and $\mathrm{Pb}$ are present, for a total contribution of about 2\% (estimated using the PyMCA software, based on the Fundamental Parameters method described by Solé et al. [5]). Quite surprisingly, we detected in all the spectra analysed a weak, but well defined, fluorescence signal from gold, which is present in the silver of the amphora at a percentage around 2\%. It's not clear why this signal was not observed in the 1986 analysis, but it's probable that the AAS instrument used at the time was not able to detect gold at the concentrations observed fifty years after, using the XRF technique. The analysis of the bottom of the amphora (Figure 8) confirmed the presence of gold around $2 \%$ and evidenced the higher concentration of lead with respect to the body of the amphora, but also $\mathrm{Cu}$ and Fe were present at higher concentrations (5\% total), which implies a lower Ag concentration in the base of the amphora with respect to the body (Figure 8 \& 9).

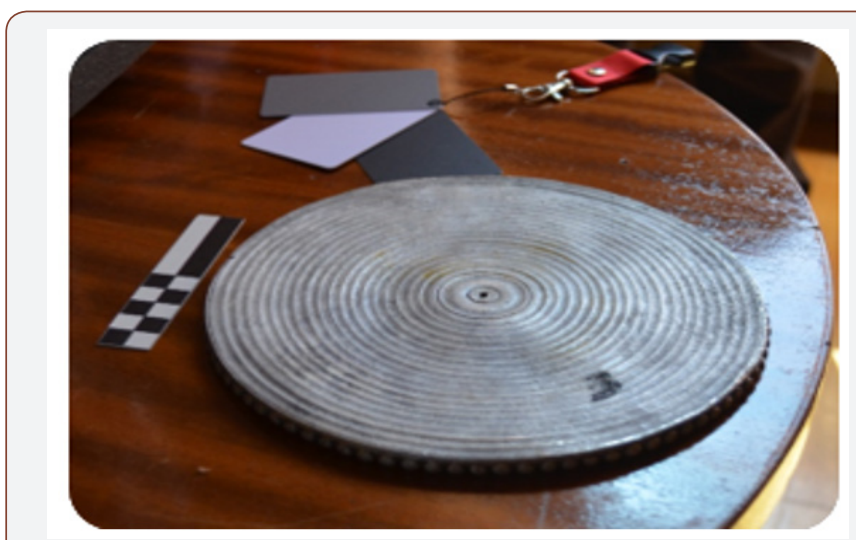

Figure 8: Bottom part of the amphora (Photo Stefano Pagnotta, all rights reserved).

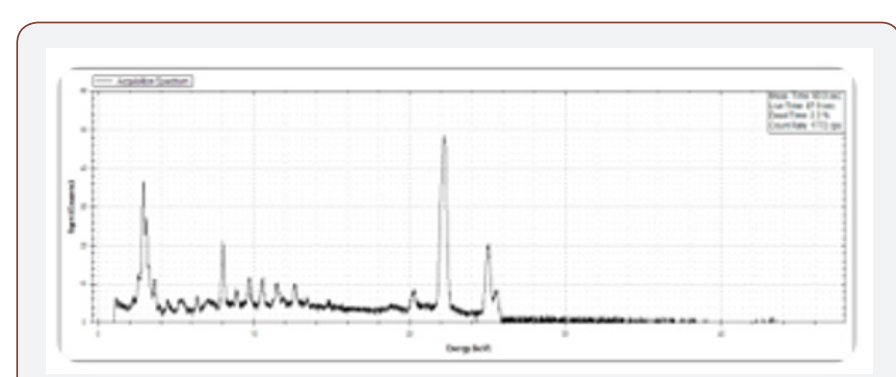

Figure 9: A typical XRF spectrum acquired on the base of the Baratti amphora. Note the square root scale on the $y$ axis.

\section{Conclusion}

At the end of this study, we should admit that the Baratti amphora has not yet revealed any of its secrets. We still don't know how the amphora was manufactured, where the amphora was going when the ship which was transporting it wrecked in the Baratti harbor, we don't know about its use, either practical or ritual, and we don't have any solid evidences about its origin. Many clues suggest that the solution of this latter mystery might be related to the exoteric nature of the amphora and the oriental myths depicted on it; however, the absence of gold in the silver of the amphora, a finding that was considered in the past as a proof of the oriental provenience of the material, was not confirmed by the most recent analysis. Consequently, the current attribution of the Baratti amphora silver to the abundant galena deposits of Anatolia [1] might be the object of new discussions. Considering that the Roman region of Upper Moesia was considered the most important mining province of the Roman empire [6] and given the similitudes with other coeval silver artifacts such as the Concești amphora and the cylinder of Viminacium, a Balkan provenience cannot be a priori excluded. After more than 50 years from its casual discovery, the only certainty is that the Baratti amphora is still a challenging object which deserves to be investigated archaeometrically in depth, through comparison with other coeval silver objects [7], trying to obtain more information about the provenience of the silver used for its realization. Only in this way, new hypothesis could be formulated about its provenience and commission. This information would, in turn, help to understand the complex series of events which have brought the amphora from its, still unknown, place of origin, through a journey on the Mediterranean, to its millennial rest on the bottom of the sea of the Baratti gulf, only interrupted in 1968 by the net of a fisherman which returned it to the admiration of the visitors of the Piombino Archaeological Museum.

\section{Acknowledgment}

None.

\section{Conflict of Interest}

No conflict of interest.

\section{References}

1. Paolo Enrico Arias (1986) L'Anfora argentea di Porto Baratti. The Bulletin of Art.

2. Giandomenico De Tommaso, Cinzia Murolo (2011) Il naufragio di un mondo. Baratti's silver amphora. Val di Cornia Parks, Piombino. Italy.

3. Legnaioli S, Garcia FA, Andreotti A, Bramanti E, Pace DD, et al. (2013) Multi-technique study of a ceramic archaeological artifact and its content. Spectrochimica Acta - Part A: Molecular and Biomolecular Spectroscopy.

4. François Baratte (1978) Remarques à propos de quelques objets GalloSilver Romans with niello decoration. Antike.

5. Solé VA, Papillon E, Cotte M, Walter Ph, Susini J (2006) A multiplatform code for the analysis of energy-dispersive X-ray fluorescence spectra.

6. Dušanić S (2003) Roman mining in Illyricum. Historical aspects. In: Dall'Adriatico al Danubio, L'Illirico nell'età greca e romana (Eds.), Proceedings of the international Cividale del Friuli conference, pp. 247270.

7. Richard Hobbs, Janet Lang, Michael J Hughes, Roger Tomlin, Jude Plouviez (2016) The Mildenhall Treasure: Late Roman Silver Plate from East Anglia. 